\title{
Study on the Properties of Micro - arc Oxidation Self - assembled Composite coatings on Magnesium Alloy
}

\author{
Wei Shang ${ }^{1,2}$, Yuanyuan Wang ${ }^{1}$, Yuqing Wen ${ }^{1, *}$, Xiaoqiang Zhan ${ }^{1}$, Dan Kong ${ }^{1}$ \\ ${ }^{1}$ Guangxi Key Laboratory of Electrochemical and Magnetochemical Function Materials, Guilin \\ University of Technology, Guilin, 541004, China \\ ${ }^{2}$ Collaborative Innovation Center for Exploration of Hidden Nonferrous Metal Deposits and \\ Development of New Materials in Guangxi, Guilin University of Technology, Guilin, 541004, China \\ "E-mail: wenyuqing16@163.com
}

doi: $10.20964 / 2017.12 .14$

Received: 27 July 2017 / Accepted: 22 September 2017 / Published: 12 November 2017

The micro-arc oxidation / bis[( $\gamma$-triethoxysilyl)propyl]tetrasulfide (BTESPT) self-assembled composite coatings were prepared on the surface of magnesium alloy by self-assembly (SAM) and micro-arc oxidation (MAO). The surface morphology and composition of the composite coatings were characterized by scanning electron microscopy (SEM) and energy dispersion spectrometry (EDS). The corrosion resistance of the composite coatings was studied by electrochemical impedance spectroscopy (EIS), polarization curves and the experiments of immersion. The test results showed the anticorrosion of the composite coatings were significantly improved compared with the pure micro-arc oxidation film. The formation mechanism of the self-assembled membrane on the micro-arc oxidation layer of magnesium alloy was investigated by dynamic simulation. The results showed that the selfassembled molecules were chemically adsorbed on the solid surface.

Keywords: Magnesium alloy, Micro-arc oxidation, Self-assembly, corrosion resistance, Dynamic simulation

\section{$\underline{\text { FULL TEXT }}$}

(C) 2017 The Authors. Published by ESG (www.electrochemsci.org). This article is an open access article distributed under the terms and conditions of the Creative Commons Attribution license (http://creativecommons.org/licenses/by/4.0/). 